\title{
Determinação do teor alcoolico e da eficácia antimicrobiana de diferentes marcas de álcool 70\% INPM
}

\section{Determination of the alcohol content and antimicrobial effectiveness of diferente 70\% INPM alcohol brands}

\author{
Liatta Macario $^{1 *}$, Ana Paula Margioto Teston ${ }^{1}$, Danielly Chierrito ${ }^{2}$, Francine Maery Dias \\ Ferreira Romanichen ${ }^{1}$, Daniela Cristina de Medeiros Araújo ${ }^{1}$.
}

\begin{abstract}
RESUMO
Os álcoois etílicos 70\% INPM são eficazes para a antissepsia das mãos e desinfecção de superfícies, sendo este o álcool mais usado como antisséptico, por atuar coagulando as proteínas da célula de microrganismos, diminuindo a tensão superficial e acarretando em lise celular pela penetração da água. O objetivo deste trabalho foi avaliar o grau alcoólico e a eficácia antimicrobiana de diferentes marcas de álcool comercial. Foram adquiridos 10 litros de diferentes marcas de álcool (1L) em supermercados e farmácias do município de Maringá (PR), em abril de 2021. Os álcoois foram nomeados de A a J, ocultando as marcas e fabricantes. Das 10 marcas analisadas, sete estavam abaixo do limite $\left(76,9^{\circ} \mathrm{GL}\right.$ a $\left.81,4^{\circ} \mathrm{GL}\right)$, sendo reprovadas nesta avaliação. Uma das amostras apresentou valores acima do limite descrito. Apenas duas marcas foram aprovadas neste parâmetro. Quanto ao $\mathrm{pH}$, os valores variaram de 4,62 a 8,15. Na análise de eficácia antimicrobiana, apenas cinco amostras apresentaram halo de inibição para E. coli. Nenhuma marca apresentou halo de inibição para Staphylococcus aureus. Desta forma, conclui-se que apenas as amostras C e D foram aprovadas no teor alcoólico e eficácia antimicrobiana contra E. coli.
\end{abstract}

Palavras-chave: Álcool etílico; Antisséptico; Alcoometria.

\begin{abstract}
The 70\% ethyl alcohols are effective for hands antisepsis and surface disinfection, being the most used alcohol as an antiseptic the 70\% INPM hydrated ethyl alcohol, as it acts coagulating cell proteins, reducing superficial tension and ending in cell lysing by water penetration. This work's objective was evaluate the alcoholic strength and antimicrobial efficacy in different brands of commercial alcohol. The 10 brands of alcohols (1 L) that were purchased in supermarkets and pharmacies in the city of Maringá (PR), in April 2021, were named from A to J, hiding brand and manufacturer. Of these, seven samples were below the limit $\left(76.9^{\circ} \mathrm{GL}\right.$ to $\left.81.4^{\circ} \mathrm{GL}\right)$, failing this evaluation. One of the samples presented values above the described parameter. Only two brands were approved for this parameter. As to the $\mathrm{pH}$, the values ranged from 4.62 to 8.15 . In the analysis of antimicrobial efficacy, only five samples showed a halo of inhibition for E. coli. No brand shows a halo of inhibition for Staphylococcus aureus. Thus, it is concluded that only samples $\mathrm{C}$ and $\mathrm{D}$ were approved in alcohol contente and antimicrobial efficacy against E. coli.
\end{abstract}

Keywords: Ethyl alcohol; Antiseptic; Alcoholic strength.

\footnotetext{
${ }^{1}$ Centro Universitário Ingá - UNINGÁ. *E-mail: liattamac@ gmail.com

${ }^{2}$ Universidade Estadual de Maringá - UEM
} 


\section{INTRODUÇÃO}

Com a pandemia do novo Coronavírus, o uso de álcool etílico $70 \%$ aumentou consideravelmente em todo mundo, sendo utilizado como antisséptico, na forma líquida ou em gel, para prevenção desta infecção (COVID-19). Quando foi decretado o início da pandemia, em março de 2020, houve uma corrida dos consumidores para compra de álcool etílico 70\%, nas formas líquida e em gel, provocando o desabastecimento destes produtos na maioria dos estabelecimentos (LIMA, 2020).

A graduação alcoólica de misturas de etanol e água pode ser representada por diferentes unidades, sendo as mais utilizadas a graduação do Instituto Nacional de Pesos e Medidas (INPM) e a graduação Gay Lussac $\left({ }^{\circ} \mathrm{GL}\right) . \mathrm{O}^{\circ} \mathrm{GL}$ corresponde ao percentual do álcool etílico em volume, ou seja, a quantidade do álcool, em mililitros, presente em $100 \mathrm{~mL}$ de uma mistura de álcool e água. Pode ser expressa em \% (v/v), como por exemplo: uma solução $80 \%{ }^{\circ} \mathrm{GL}$ contém $80 \mathrm{~mL}$ de álcool etílico em $100 \mathrm{~mL}$ da solução (mistura de álcool e água). Já o INPM representa o percentual em massa, ou seja, a quantidade de álcool, em gramas, presente em 100 gramas de uma mistura de álcool e água. Pode ser expressa em \% (m/m), como por exemplo: uma solução 90\% INPM tem 90 gramas de álcool etílico em 100 gramas da solução (mistura de álcool e água). (BRASIL, 2012).

Segundo a Resolução de Diretoria Colegiada (RDC) n ${ }^{0}$ 350, de 19 de março de 2020, o álcool etílico hidratado $70^{\circ}$ INPM, é adequado para uso como antisséptico, sanitizante ou desinfetante devido às suas propriedades químicas (BRASIL, 2020). Apresenta uma atividade bactericida devido a coagulação das proteínas das bactérias, e tem uma ação fungicida e virucida em poucos vírus, sendo utilizado em combinação com outros antissépticos para aumentar a eficiência (MORIYA, MÓDENA, 2008; TORTORA; CASE; FUNKE, 2017; ARAÚJO; MELO; FORTUNA, 2019).

Em concentrações muito altas, o álcool etílico pode provocar a morte precoce das células epiteliais, porém, na concentração de $70 \%(\mathrm{~m} / \mathrm{m})$, exerce uma ação antisséptica e não agride os tecidos epiteliais, sendo recomendado para assepsia das mãos e desinfecção de superfícies (SANTOS, 2002).

O álcool etílico hidratado $70^{\circ}$ INPM proporciona desinfecção de superfícies e antissepsia da pele, tendo características microbicidas capazes de eliminar os microrganismos que estão envolvidos nas infecções relativas aos procedimentos 
assistenciais, sendo essencial na desinfecção e antissepsia de artigos médico hospitalares (SANTOS, 2002; KONKEWICZ, 2007; BRASIL, 2010a).

Em 2002 a Agência Nacional de Vigilância Sanitária (Anvisa) proibiu a comercialização de álcool $70 \%$ na forma líquida, para reduzir o risco de acidentes. Porém, diante da pandemia, em 2020 a Agência autorizou novamente a venda. Porém, deve ser usado de forma cautelosa, sendo mantidos longe do alcance das crianças, para evitar queimaduras e ingestão (HIRAIFARMA, 2020).

Desse modo, além do álcool 70\% ser um bom antisséptico, ele é simples de usar, tem baixo custo, fácil aquisição, simples aplicação e tem toxicidade reduzida, sendo viável tanto a nível hospitalar como para uso em clínicas, consultórios e residências (KALIL, COSTA, 1994; SANTOS, 2002; BRASIL, 2010a; GRAZIANO et al. 2013; ARAÚJO; MELO; FORTUNA, 2019). Diante do exposto, o objetivo deste trabalho foi avaliar o grau alcoólico e a eficácia antimicrobiana de diferentes marcas de álcool comercial.

\section{MATERIAL E MÉTODOS}

\section{Matéria-prima}

Os álcoois $(1 \mathrm{~L})$ de dez diferentes marcas foram adquiridos em supermercados e farmácias do município de Maringá (PR), em abril de 2021. Foram nomeados de A a J, ocultando as marcas e fabricantes.

\section{Avaliação dos Rótulos}

Existem algumas informações obrigatórias que devem estar contidas nos rótulos de álcoois $70 \%$ comerciais. São elas: nome, categoria do produto, informações tecnológicas, modo de usar, primeiros socorros, lote e data de fabricação, prazo de validade, técnico responsável, fabricante, AFE (autorização de funcionamento de empresa) e o número de registro (saneante) (NOTA TÉCNICA, 2020). Foram verificadas se todas estas informações estavam descritas nos rótulos dos produtos.

\section{Determinação do $\mathrm{pH}$}


Para avaliação do valor do $\mathrm{pH}$ das amostras, utilizou-se um pHmetro previamente calibrado. Antes da verificação do valor do $\mathrm{pH}$, as amostras foram colocadas em um béquer de $100 \mathrm{~mL}$ e mantidas em temperatura ambiente. O eletrodo foi imerso na amostra, sendo consideradas três leituras sucessivas das amostras testada (BRASIL, 2004).

\section{Determinação do grau alcoólico}

A determinação da graduação alcoólica foi realizada utilizando alcoômetro Gay Lussac, aparelho que mede a concentração alcoólica em uma mistura de álcool e água. Para ajuste da graduação de acordo com a temperatura do líquido, foi utilizada a tábua da força real dos líquidos espirituosos (BRASIL, 2012).

\section{Determinação da eficácia antimicrobiana}

Para determinar a eficácia antimicrobiana foi utilizado o método de disco difusão. Em placas de Petri contendo ágar Mueller Hinton, foram incubadas as bactérias Escherichia coli e Staphylococcus aureus. Após, foi adicionadoum disco de papel estéril embebido em álcool $70 \%(\mathrm{~m} / \mathrm{m})$ na placa. Após a secagem do álcool na placa, em temperatura ambiente, foi incubado a $35^{\circ} \mathrm{C}$ por 48 horas e realizada a medida do halo de inibição. As análises foram realizadas em triplicata.

\section{RESULTADOS E DISCUSSÃO}

\section{Avaliação dos Rótulos}

Segundo a RDC $N^{\circ}$ 46/2002 deve estar contida na rotulagem do álcool etílico 70\%: nome comercial completo, destinação do álcool; graduação alcoólica em graus INPM; advertências toxicológicas: frases obrigatórias, recomendação de segurança, modo de usar, primeiros socorros, lote e data de fabricação, prazo de validade, nome do responsável técnico com o número do registro no órgão competente; razão social, endereço do fabricante e CNPJ (BRASIL, 2002). 
Na tabela 1 estão demonstrados os resultados da análise dos rótulos feita com as 10 marcas de álcool etílico 70\%. Quatro marcas de álcool, sendo elas A, C, G e H, foram aprovadas por apresentarem todas as informações necessárias descritas no rótulo do produto. As amostras $\mathrm{D}, \mathrm{H}$ e $\mathrm{I}$ não apresentaram o número de autorização de funcionamento da empresa (AFE). As amostras B, E, F e H não apresentaram o número de registro do produto.

Tabela 1. Resultado da análise dos rótulos das diferentes marcas de álcool.

\begin{tabular}{|c|c|c|c|c|c|c|c|c|c|c|}
\hline Marca & $\bar{A}$ & $\mathbf{B}$ & $\mathbf{C}$ & $\overline{\mathbf{D}}$ & $\bar{E}$ & $\mathbf{F}$ & $\mathbf{G}$ & $\mathbf{H}$ & $\mathbf{I}$ & $\mathbf{J}$ \\
\hline \multicolumn{11}{|l|}{ Nome e/ou } \\
\hline Marca do & Sim & Sim & Sim & Sim & Sim & Sim & Sim & Sim & Sim & Sim \\
\hline Produto & & & & & & & & & & \\
\hline $\begin{array}{c}\text { Categoria do } \\
\text { Produto }\end{array}$ & Sim & Sim & Sim & Sim & Sim & Sim & Sim & Sim & Sim & Sim \\
\hline $\begin{array}{l}\text { Informações } \\
\text { Toxicológicas }\end{array}$ & Sim & Sim & Sim & Sim & Sim & Sim & Sim & Sim & Sim & Sim \\
\hline Modo de Usar & Sim & Sim & Sim & Sim & Sim & Sim & Sim & Sim & Sim & Sim \\
\hline $\begin{array}{l}\text { Primeiros } \\
\text { Socorros }\end{array}$ & Sim & Sim & Sim & Sim & Sim & Sim & Sim & Sim & Sim & Sim \\
\hline $\begin{array}{l}\text { Lote e Data de } \\
\text { Fabricação }\end{array}$ & Sim & Sim & Sim & Sim & Sim & Sim & Sim & Sim & Sim & Sim \\
\hline $\begin{array}{l}\text { Prazo de } \\
\text { Validade }\end{array}$ & Sim & Sim & Sim & Sim & Sim & Sim & Sim & Sim & Sim & Sim \\
\hline $\begin{array}{c}\text { Técnico } \\
\text { Responsável }\end{array}$ & Sim & Sim & Sim & Sim & Sim & Sim & Sim & Sim & Sim & Sim \\
\hline Fabricante & Sim & Sim & Sim & Sim & Sim & Sim & Sim & Sim & Sim & Sim \\
\hline AFE & Sim & Sim & Sim & Não & Sim & Sim & Sim & Não & Não & Sim \\
\hline $\mathbf{N}^{\circ}$ de Registro & & & & & & & & & & \\
\hline $\begin{array}{c}/ \mathrm{N}^{\circ} \text { de } \\
\text { Processo }\end{array}$ & Sim & Não & Sim & Sim & Não & Não & Sim & Não & Sim & Sim \\
\hline
\end{tabular}




\section{Avaliação do pH}

$\mathrm{O}$ valor de $\mathrm{pH}$ de uma amostra representa a acidez ou a alcalinidade desta amostra. A escala de $\mathrm{pH}$ vai de 1 (ácido) a 14 (alcalino), e o valor 7 significa que o pH é neutro (GISCH et al., 2017). Os valores de $\mathrm{pH}$ encontrados para as amostras analisadas estão descritos na Tabela 2.

Tabela 2. Resultado do pH das diferentes marcas de álcool.

\begin{tabular}{lllllllllll}
\hline Marca & A & B & C & D & E & F & G & H & I & J \\
\hline Média & 8,02 & 8,15 & 7,30 & 7,74 & 6,23 & 7,70 & 6,01 & 6,86 & 4,62 & 5,73 \\
Desvio & 0,14 & 0,14 & 0,1 & 0,14 & 0,14 & 0,1 & 0,14 & 0,1 & 0,14 & 0,1 \\
padrão & & & & & & & & & & \\
\hline
\end{tabular}

Nas marcas analisadas é possível observar que as amostras A e B apresentaram o valor de $\mathrm{pH}$ alcalino, enquanto as amostras I, e $\mathrm{J}$ apresentaram um valor de $\mathrm{pH}$ ácido. $\mathrm{O}$ restante das amostras apresentou $\mathrm{pH}$ próximo do neutro. Apenas a amostra $\mathrm{J}$ obteve $\mathrm{pH}$ próximo ao valor esperado de 5,5 a 5,9 (ANDRADE et al., 2002).

Souza, Xavier e Camargo (2019) obtiveram valores de pH de 7,38; 7,64 e 6,20 para amostras de álcool 70\% líquido. Neste trabalho os autores avaliaram a concentração e eficácia do álcool $70 \%$.

Gisch et al (2017) em um estudo de caracterização e eficácia de álcool gel, obtiveram valores de $\mathrm{pH}$ das amostras analisadas variando entre 6,4 a 7,8, próximos aos valores obtidos para amostras de álcool líquido no presente trabalho.

De acordo com Andrade et al (2002) que realizaram uma revisão de literatura sobre a produção de álcoois com ênfase na sua atividade antimicrobiana, o álcool etílico $70 \%$ tem uma atividade bactericida rápida na temperatura ambiente, com $\mathrm{pH}$ ideal em torno de 5,5 a 5,9 .

Determinação do grau alcoólico 
A alcoometria é a determinação do grau alcoólico ou título etanólico do conjunto de álcool e água. É representado pelo número de volumes de álcool etílico a $20^{\circ} \mathrm{C}$ incluído em 100 volumes desse conjunto a mesma temperatura. É expresso em \% (v/v) (BRASIL, 2019).

A análise de alcoometria foi realizada nas 10 marcas de álcool adquiridas, utilizando alcoômetro Gay Lussac. Após a verificação da graduação alcoólica e temperatura do líquido, foi feito o ajuste utilizando a tábua da força real dos líquidos espirituosos. Os valores obtidos estão descritos na tabela 3.

Tabela 3. Resultado da graduação alcoólica das diferentes marcas de álcool.

\begin{tabular}{cllllllllll}
\hline Marca & $\mathbf{A}$ & $\mathbf{B}$ & $\mathbf{C}$ & $\mathbf{D}$ & $\mathbf{E}$ & $\mathbf{F}$ & $\mathbf{G}$ & $\mathbf{H}$ & $\mathbf{I}$ & $\mathbf{J}$ \\
\hline $\begin{array}{c}\text { Temperatura } \\
\text { Volume }\end{array}$ & $26^{\circ} \mathrm{C}$ & $26^{\circ} \mathrm{C}$ & $25^{\circ} \mathrm{C}$ & $25^{\circ} \mathrm{C}$ & $25^{\circ} \mathrm{C}$ & $26^{\circ} \mathrm{C}$ & $25^{\circ} \mathrm{C}$ & $26^{\circ} \mathrm{C}$ & $27^{\circ} \mathrm{C}$ & $27^{\circ} \mathrm{C}$ \\
$\begin{array}{c}\text { alcoômetro } \\
\text { Tábua }\end{array}$ & 79 & 75 & 83 & 81 & 88 & 77 & 79 & 76 & 79 & 80 \\
Aprovado & $\mathbf{N a ̃ o}$ & $\mathbf{N a ̃ o}$ & $\mathbf{S i m}$ & $\mathbf{S i m}$ & $\mathbf{S i m}$ & $\mathbf{N a ̃ o}$ & $\mathbf{N a ̃ o}$ & $\mathbf{N a ̃ o}$ & $\mathbf{N a ̃ o}$ & $\mathbf{N a ̃ o}$ \\
\hline
\end{tabular}

Os resultados obtidos demonstraram que as marcas A, B, F, G, H, I e J apresentaram valores de graduação alcoólica abaixo do permitido pela legislação e do que o indicado na embalagem do produto. Já a amostra E apresentou valor acima do permitido. Sendo assim, apenas as amostras C, D e E foram aprovadas, apresentando graduação alcoólica dentro do limite estabelecido para eficácia do produto.

Em estudo semelhante realizado por Scarabelli et al. (2012), foram analisadas vinte amostras de álcool $70 \%$ contendo $50 \mathrm{~mL}$ cada, distribuídos em farmácias dos municípios de São Jorge do Ivaí, Ourizona e Mandaguaçu (PR). A graduação alcoólica observada variou entre $62,6 \%$ e $90,7 \%$, sendo que apenas nove amostras foram aprovadas.

Em outro estudo realizado por Tiyo et al. (2009) foram analisadas cinquenta amostras de álcool $70 \%$ no laboratório de química analítica da faculdade Uningá, 
utilizados para a assepsia nas farmácias e drogarias da cidade de Maringá (PR). Das 50 amostras, apenas 21 estavam dentro do valor estabelecidos para que essas amostras de álcool exerçam sua atividade tanto para a assepsia quanto para desinfecção.

Segundo Vieira et al (2007), que avaliaram amostras de álcool líquido $70^{\circ} \mathrm{GL}$ comercialmente disponível em Minas Gerais, $60 \%$ das amostras não estavam de acordo com a graduação alcoólica descrita no rótulo do produto.

A não conformidade dos álcoois que foram analisados e reprovados pode ser explicada por diversos fatores, que comprometem a qualidade do produto, como: não cumprimento das técnicas de diluição do álcool, embalagem imprópria, não aplicação das boas práticas de fabricação, estocagem inadequada da matéria-prima, uso de água não purificada, entre outros (DOURADO, 2011; FERRARINI, 2014).

Neste contexto, a RDC n 42/2010 dispõe sobre a aprovação da obrigatoriedade de disponibilização de preparação alcoólica para fricção antisséptica das mãos, pelos serviços de saúde do País. O objetivo é promover e instituir a higienização das mãos, por meio da preparação alcoólica para a fricção das mãos, conforme as diretrizes da Organização Mundial de Saúde Prevista na Aliança Mundial (OMSPAM) para a segurança dos pacientes e profissionais da saúde, além do controle de infecções (BRASIL, 2010b).

\section{Avaliação da eficácia antimicrobiana}

A atividade antimicrobiana do álcool etílico $70 \%$ frente aos microrganismos potencialmente patogênicos, é fundamental para as estratégias em vista ao uso racional de desinfetantes nos serviços de saúde e antissépticos (REIS et al, 2011).

O método de disco difusão é bastante utilizado para realização de teste de sensibilidade a antimicrobianos. Esse teste é o mais utilizado nas rotinas dos laboratórios, pois é adequado para diversos patógenos bacterianos (BrCAST, 2021).

O resultado dos testes microbiológicos realizados com $S$. aureus e E. coli podem ser observados na tabela 5 . 
Tabela 5. Resultado encontrados no teste microbiológico.

\begin{tabular}{lllllllllll}
\hline Amostras & A & B & C & D & E & F & G & H & I & J \\
\hline S. Aureus & - & - & - & - & - & - & - & - & - & - \\
E. Coli & $>9 \mathrm{~mm}$ & $>9 \mathrm{~mm}$ & $<9 \mathrm{~mm}$ & $>11 \mathrm{~mm}$ & - & - & - & - & $<9 \mathrm{~mm}$ & - \\
\hline
\end{tabular}

Podemos observar que as amostras A, B, C, D e I apresentaram halo de inibição para E. coli. Amostras A e B apresentaram halo de inibição maior que 9 mm (milímetros) e amostra C e I apresentaram halos menores que $9 \mathrm{~mm}$. A amostra D foi a que apresentou maior halo de inibição $(11 \mathrm{~mm})$. Nenhuma amostra apresentou halo de inibição para $\mathrm{S}$. aureus (Figuras 1 e 2).

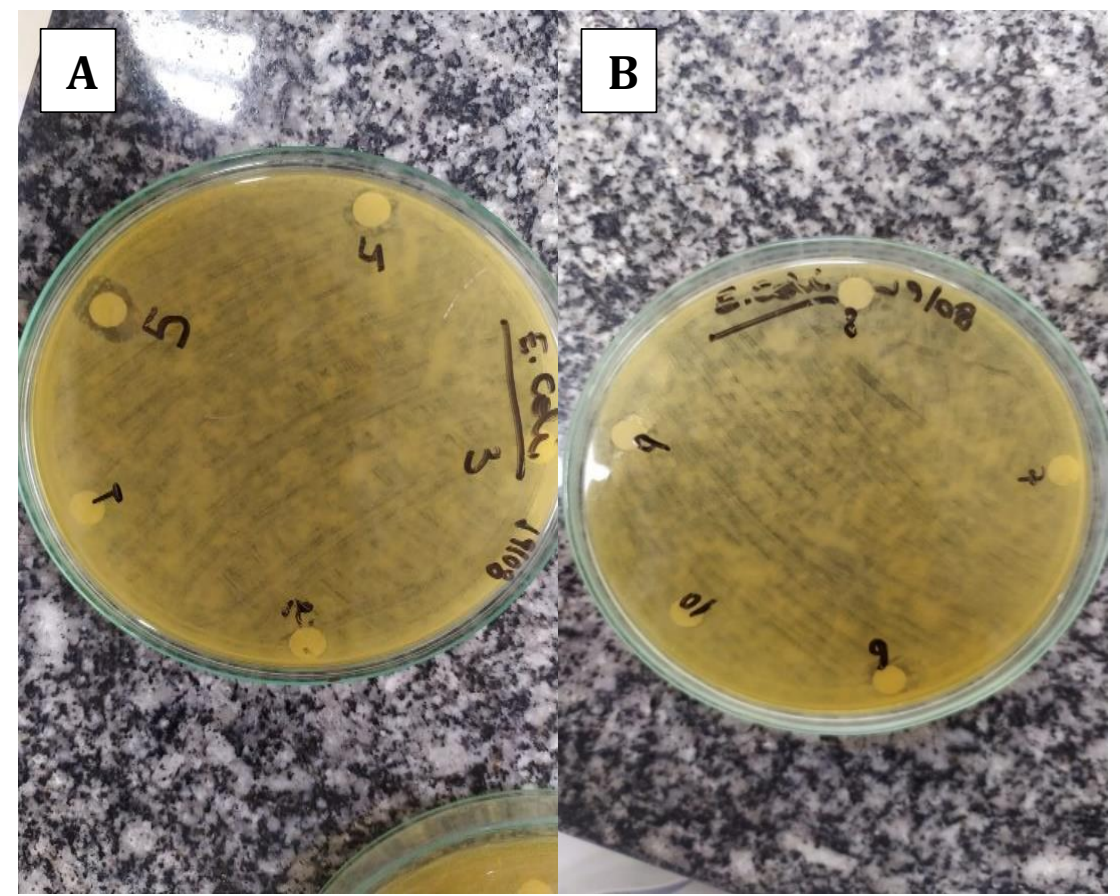

Figura 1. A: Placa com disco de fusão contendo as amostras H (1), F (2), E (3), B (4) e D (5). B: Placa com disco de fusão contendo as amostras C (6), J (7), A (8), I (9) e G (10). As amostra B (4), D (5), C (6), A (8) e I (9) apresentaram halo de inibição para Escherichia coli. 


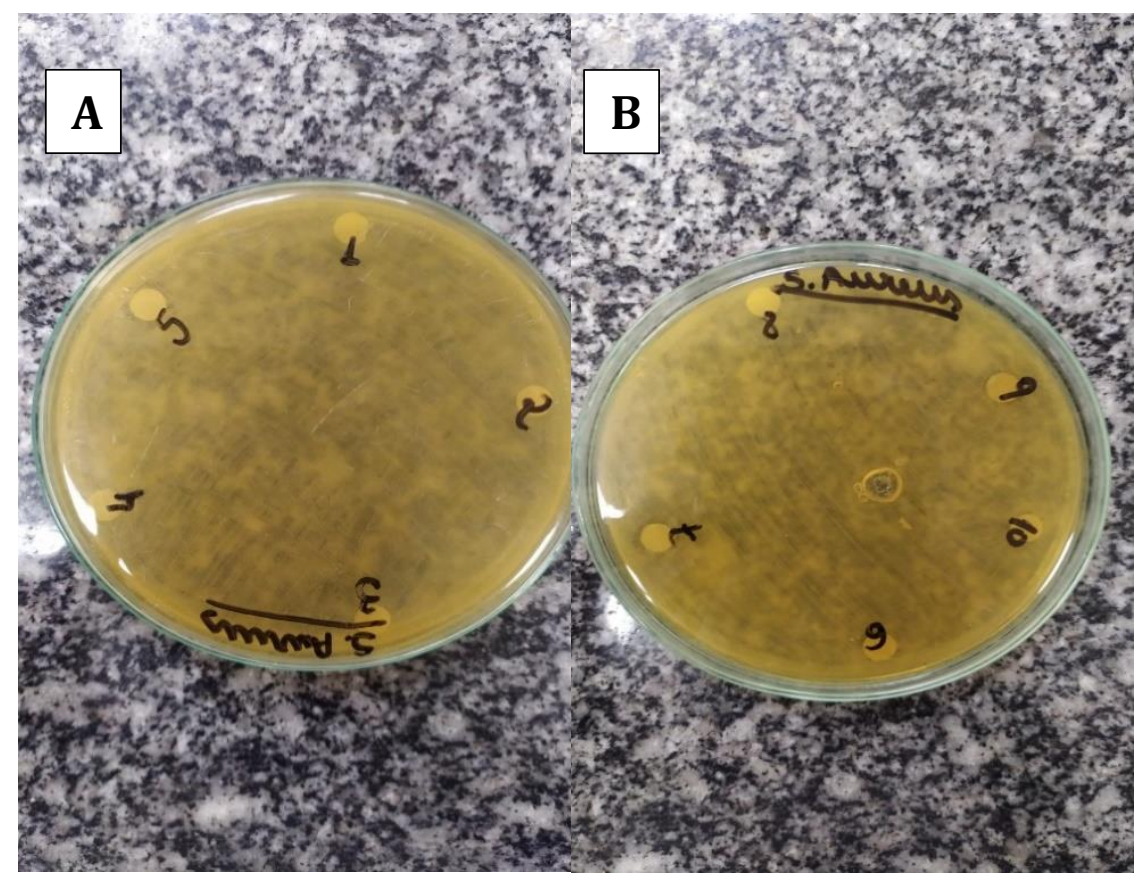

Figura 2. A: Placa com disco de fusão contendo as amostras H (1), F (2), E (3), B (4) e D (5). B: Placa com disco de fusão contendo as amostras C (6), J (7), A (8), I (9) e G (10). Nenhuma amostra apresentou halo de inibição para Staphylococcus aureus.

A resistência da bactéria Staphylococcus aureus a desinfecção com álcool etílico $70 \%$ pode estar associada à composição de sua parede celular, uma vez que bactérias Gram positivas possuem uma espessa camada de peptideoglicano, o que prejudica a penetração do álcool (BERNARDI; COSTA, 2017).

Em estudo realizado por Rosado e Silva (2016), foi avaliada a eficácia de antissépticos nas mãos de profissionais de saúde de hospitais particulares da cidade de Teresina (PI). A análise foi realizada com coleta de impressão do polegar em placa de petri, antes e após a higienização. A aplicação de álcool $70 \%$ líquido nas mãos resultou em redução de 80,99\% no número de UFCs.

Em estudo realizado por Sousa, Xavier e Camargo (2019) que avaliaram a concentração e eficácia do álcool $70 \%$ contra microrganismos Gram negativo e Gram positivo, apenas uma das três marcas de álcool $70 \%$ líquido analisadas apresentou halo de inibição contra Staphylococcus aureus e Escherichia coli. 


\section{CONCLUSÕES}

Desde o início da pandemia pelo coronavírus, as Agências de Saúde em todo o mundo recomendam o uso de álcool 70 para desinfetar superfícies inertes nos estabelecimentos comerciais, residências e nos locais de trabalho, que podem estar contaminadas pelo vírus. A não conformidade dos álcoois observada neste estudo pode estar relacionada ao não cumprimento das técnicas de diluição, embalagem imprópria, ou ao não cumprimento das boas práticas de fabricação, além de matéria-prima de qualidade inadequada, estocagem com temperaturas incorretas, uso de água não purificada, entre outros.

\section{REFERÊNCIAS}

ANDRADE D.; et al. Álcoois: a produção do conhecimento com ênfase na sua atividade antimicrobiana. Revista Medicina, v. 35, n. 1, 2002.

ARAÚJO, L. F.; MELO, T. N. L; FORTUNA, J. L. Avaliação da eficácia do álcool comercial para desinfecção de superfícies. Revista Científica do ITPAC, v.12, n.2, pub.7, p. 66-71, 2019.

BERNARDI, G. A.; COSTA, T. C. M. Avaliação da atividade antimicrobiana do álcool $70 \%$ em superfícies contaminadas. Journal of Infection Control, v. 6, n. 4, p. 1-11, 2017.

BRASIL. Resolução de Diretoria Colegiada (RDC) n 46, de 20 de fevereiro de 2002. Dispõe sobre as frases e informações obrigatórias para os dizeres dos rótulos. 2002.

BRASIL. Agência Nacional de Vigilância Sanitária (ANVISA). Guia de Estabilidade de Produtos Cosméticos. 1. ed. Brasília: Anvisa, 2004.

BRASIL. Agência Nacional de Vigilância Sanitária (ANVISA). Segurança do Paciente em Serviços de Saúde: Limpeza e Desinfecção de Superfícies. Brasília, p.116, 2010a.

BRASIL. Ministério da Saúde. Agência Nacional de Vigilância Sanitária. Resolução de Diretoria Colegiada (RDC) $n^{\circ} 42$, de 25 de outubro de 2010. Dispõe sobre a obrigatoriedade de disponibilização de preparação alcoólica para fricção antisséptica das mãos, pelos serviços de saúde do País, e dá outras providências. 2010 b.

BRASIL, Ministério da Saúde, Agência Nacional de Vigilância Sanitária (ANVISA). Formulário Nacional da Farmacopeia Brasileira, 2 ed., Brasília, 2012. 
BRASIL. Ministério da Saúde. Agência Nacional de Vigilância Sanitária (ANVISA). Farmacopeia Brasileira, v. 1 e 2, 60 ed. Brasília, 2019.

BRASIL. Ministério da Saúde. Agência Nacional de Vigilância Sanitária. Resolução de Diretoria Colegiada (RDC) n 350 , de 19 de março de 2020.

Brazilian Committee on Atimicrobial Susceptibility Testing (BrCAST). Teste de sensibilidade aos antimicrobianos. Método de disco-difusão. Versão 9.0 do EUCAST, janeiro 2021.

DOURADO, R. Esterilização de instrumentos e desinfecção de artigos odontológicos com ácido peracético. Journal of Biodentistry and Biomaterials, n. 2, p. 31-45, 2011.

FERRARINI, M. Estabilidade de álcool 77\% (v/v) em almotolias e borrifadores. III Simpósio de Ciências farmacêuticas. Centro Universitário São Camilo, 2014.

GISCH, C. et al. Caracterização e eficácia de álcool gel. Revista Cosmetics e Toiletries, v. 29, p. 48-54, 2017.

GRAZIANO, M. U. et al. Eficácia da desinfecção com álcool 70\% (p/v) de superfícies contaminadas sem limpeza prévia. Revista Latino-Americana de Enfermagem, v. 21, n. 2, 2013.

HIRAIFARMA. Determinação do álcool 70\% utilizado para antissepsia em drogarias e farmácias de Maringá- Paraná. Rio de Janeiro, 2012.

KALIL, E. M.; COSTA, A. J. F. Desinfecção e esterilização. Acta Ortopédica Brasileira, v. 2, n. 4, p.1-4, 1994.

KONKEWICZ, L. R. Controle de infecção em odontologia: antissépticos e desinfetantes. In: WANNMACHER, L.; FERREIRA, M. B.C. (Ed.). Farmacologia clínica para dentistas. 3. ed. Rio de janeiro: Guanabara Koogan, p. 333-350, 2007.

LIMA, L. S. O.; ALMEIDA, R. K. S.; FRANCINE S. A. DA FONSECA, F. S. A.; GONÇALVES, C. C. S. A química dos saneantes em tempos de COVID-19: você sabe como isso funciona? Química Nova, v. 43, n. 5, p. 668-678, 2020.

MORIYA T.; MÓDENA J. L. P. Assepsia e Antissepsia: Técnicas de Esterilização. In: SIMPÓSIO: FUNDAMENTOS EM CLÍNICA CIRÚRGICA - $1^{\text {a }}$ Parte, v. 41, n. 3 , p. $265-73,2008$. 
NOTA TÉCNICA SVS/DVS n 009/2020 - Orientações para a identificação e consumo do álcool $70^{\circ}$ no contexto da COVID. 2020.

ROSADO, A. V.; SILVA, F. L. A avaliação da eficácia de antissépticos nas mãos dos profissionais de saúde. Revista Saúde em Foco, v. 3, n. 1, p. 1-19, 2016.

REIS, L. M.; et al. Avaliação da atividade antimicrobiana de antissépticos e desinfetantes utilizados em um serviço público de saúde. Revista Brasileira de Enfermagem, 2011.

SANTOS, A. A. M.; et al. Importância do álcool no controle de infecções em serviços de saúde. Revista de Administração em Saúde, v. 4, n. 16, p. 7-14, 2002.

SCARABELLE, S.; TIYO; TAQUARTO. Determinação do álcool 70\% utilizado para antissepsia nas farmácias de São Jorge do Ivaí, Ourizona e Mandaguaçu-Paraná.

Revista Uningá. v. 11, ed. 2, p. 124-130, 2012.

SOUZA, D. M.; XAVIER, T. T. D.; CAMARGO, E. E. S. Avaliação da concentração e eficácia do álcool $70 \%$ contra microrganismos gram negativo e gram positivo. Revista Saberes da UNIJIPA, v. 15, 2019.

TIYO, R., et al. Determinação do álcool 70\% utilizado para antissepsia em drogarias e farmácias de Maringá-Paraná. Revista Brasileira de Farmácia, v. 90, n. 3, p. 231-235, 2009.

TORTORA, J.; CASE, FUNKE, R. Microbiologia. 12. ed. Porto Alegre: Artmed. 2017.

VIEIRA, M. P. A.; et al. Análise comprobatória da graduação de soluções comerciais hidroalcoólicas a $70^{\circ}$ de Gay Lussac. In: IV Encontro de Iniciação Científica FAMINAS da Zona da Mata - MG e I Encontro de Pós-Graduação FAMINAS. 2007. 